\title{
Inside a self-improving school system: Collaboration, competition and transition
}

\author{
Mark Hadfield $^{1}$ (D) Mel Ainscow ${ }^{2}$
}

Published online: 30 August 2018

(c) The Author(s) 2018

\begin{abstract}
The idea that school systems should become self-improving is a growing trend internationally. Put simply, this involves the strengthening of links between schools so that they can provide mutual support and challenge. So far, however, there is little research that throws light on what is involved in attempts to introduce this approach for the first time. Drawing on its authors' privileged access over a 4-year period, this paper analyses what happened as one education system explored such a move. In particular, it looks at the challenges involved in strengthening collaboration between schools within policy contexts that continue to emphasise competition as a means of achieving improvements. It also examines the nature of the transitional arrangements that are required in order to move from existing organisational conditions to more collaborative ways of working. Drawing on lessons from these experiences, the paper concludes with a series of principles that are intended be useful to those in other policy contexts that are involved in introducing similar reforms.
\end{abstract}

Keywords Collaboration · Networked learning · Organisational learning $\cdot$ System reform

\section{Introduction}

Recent years have seen the emergence of new thinking regarding how best to improve national education systems (Mourshed et al. 2010). Much of this is focused on the challenge of improving outcomes for disadvantaged learners. This has led to a growing interest globally in the idea of school autonomy (Salokangas and Ainscow 2017). Usually this is set within policy contexts that intensify competition between schools, informed by high stakes accountability arrangements (Lingard and

Mark Hadfield

HadfieldM@cardiff.ac.uk

1 School of Social Sciences, Glamorgan Building, Cardiff University, King Edward VII Avenue, Cardiff CF10 3WT, UK

2 University of Manchester, Manchester, UK 
Lewis 2016). At the same time, there is also increased emphasis on schools working together, in partnerships and networks, to support one another's improvement efforts (Hadfield and Chapman 2009; Rincón-Gallardo and Fullan 2016).

These trends in education policy reflect a professional belief in the efficacy of locally generated solutions to systemic issues, such as student under-achievement. In the United Kingdom, this has resulted in a number of regional 'Challenges' (Claeys et al. 2015). This phenomenon of groups of schools coming together to grapple with systemic improvement issues is one expression of a broader policy shift, signalled most clearly in England in a White Paper of the need to "create a school system which is more effectively self-improving" (DfE 2010, para 7.4)

This paper examines what is involved in such a policy change through an analysis of a system change development in one region of Wales. ${ }^{1}$ In it, we draw on our unique experiences as academics working within the initiative, using research knowledge and processes to assist in its design, implementation and evaluation. This provided us with opportunities to study the transitional dynamics of an education system as it attempted to move from a bureaucratic and centralised approach to school improvement, to a polycentric approach led by clusters and networks of schools.

The paper focuses on two aspects of the region's attempts to transform itself into a self-improving system. Firstly, the transition occurred in a context marked by a particular mix of collaboration and competition. Although the study of how competition and collaboration coexist and interact is well-established in the private sector (Huxham and Vangen 2004), the influence on the development of education systems is an emergent area of study containing limited empirical research (Muijs and Rumyantseva 2014). This therefore led us to pose the question: How does a mix of collaboration and competition effect attempts to develop a more self-improving education system?

Secondly, a key feature of the development of collaborative improvement initiatives-within education systems (NFER 2007: Claeys et al. 2015), and in the business sector (Asheim 2002) - has been the creation of temporary intermediary structures. These are intended to support innovation and improvement by cohering, aligning and developing the existing capacities within a locality. In the region under study, an intermediary structure was created to provide a bridge between the 'old' bureaucratic system, and the establishment of 'new' polycentric one (Ostrom 2010). The structure was intended to gradually replace the existing centralised school improvement system by re-landscaping the local system in order to encourage greater collaboration. This led us to focus on a second question: What form of intermediary structure can help an education system to become self-improving?

\footnotetext{
${ }^{1}$ It should be noted that the four countries that make up the United Kingdom (England, Northern Ireland, Scotland and Wales) each have their own education policies.
} 


\section{The Welsh context}

Wales shares a close political and social history with the rest of Great Britain, and almost everyone speaks English. However, the country has retained a distinct cultural identity and is officially bilingual, with Welsh being spoken by about $20 \%$ of the population, mostly in the north and west of the country. Although it is part of the United Kingdom, Wales has a form of self-government, created in 1998 following a referendum. It also has its own national education policies. There are 22 local authorities responsible for a range of public services, including education. As we explain, occasional tensions between national and local decision-making regarding education policies are relevant to the account that follows.

Like many school systems that are seen to be successful (e.g. Alberta, Finland, Hong Kong, Singapore), Wales is relatively small, with about 3.1 million inhabitants. Despite the potential advantage of its size, however, the performance of the school system is a cause for concern, particularly in terms of outcomes for learners from low-income families, as noted in a country review conducted by OECD (2014). Some $20 \%$ of pupils are eligible for free school meals (eFSM), the proxy measure for low income families used by the education system in Wales. Most significantly, the review argued that whilst the pace of reform in recent years has been high, it has lacked a long-term vision, an adequate school improvement infrastructure, and a clear implementation strategy that all stakeholders share. Concern was also expressed that Wales had struggled to strike a balance between accountability and improvement.

In the main, the Welsh system, although underperforming in international comparisons, is still relatively equitable in the sense that 'the performance of 15-yearold students is not as closely related to their socio-economic background as it is in most other OECD countries' (OECD 2014: 21), and inclusive, in that the majority of students attend a local neighbourhood school. The OECD review, after noting these positive features, suggested a number of concrete policy options that would strengthen the Welsh education system over the longer term. In particular, it argued for the development a long-term vision, translated into measurable objectives. With this in mind, the Welsh government published a 5-year reform plan (DfES 2014). This provided a timeline for key activities and identifies immediate measures to be taken.

A key element of the plan was the government's own interpretation of the idea of a self-improving school system, which, it argues, involves:

- Transforming school improvement from being something that was once 'done to' schools to something that is being 'done by' schools.

- An end to the top-down improvement 'service' being delivered to schools and instead seek to empower school leaders to work together, taking control of their futures and their development.

- Those within schools taking responsibility for raising standards within their own organisations. 
- A strengthening of the partnerships between schools, such that they are able to support and challenge one another. (DfES 2014, p. 21)

The model proposed by the government lacked any detail as to how such new collaborative arrangements should be developed or co-ordinated, except that this would form part of the work of the new regional school improvement structures it had initiated earlier.

Following a review of existing arrangements (DfES 2013), it was decided that the school improvement services of the existing 22 local authorities would be grouped together in four regional consortia. The consortia were allowed a degree of freedom as to how they operated in practice, and received varying degrees of support and autonomy from the local authorities with which they are associated.

Early on in the development of the regional consortia, concerns were raised about their understanding of and commitment to the proposed new way of working. A report for Welsh Government (Hill 2013) described the arrangements as being 'profoundly unsatisfactory' (p. 14), since too much of the existing collaborative work between schools was of the 'come and see what we are doing' variety, rather than being based around leaders and teachers sharing data and then working jointly to improve learning.' (Hill 2013, p. 63). The consortia were also criticised for spending their budgets on appointing 'system leaders', often local authority staff, rather than investing in effective collaborative school improvement processes.

For the new approach to work effectively, it was argued, regional partnership had to create their own collaborative arrangements that reflected local needs. At the national level, however, an apparent lack of trust between different tiers in the system limited the sharing of issues and possible solutions (Evans 2015; Wales Audit Office 2015). This also contributed to the consortia becoming defensive about the difficulties they faced and led to competition between them, as they set out to prove their effectiveness as new school improvement services (Dixon 2016). Meanwhile, at the local level, consortia faced the issue of how to balance their role in developing collaborative working between schools with challenging school's that under-performed according to national accountability measures. This was a balance the national inspection service felt they had initially failed to get right in their assessments of the consortia, when they came to the conclusion that they were 'better at challenging schools about their current performance than supporting them to improve.' (Estyn 2015, p. 7).

Questions of trust also arose locally between schools, local authorities and the consortia. This seemed to be influenced by experiences in previous reform eras, when policies had swung sharply between encouraging local collaboration to imposing centrally prescribed accountability measures (Dixon 2016). Uncertainty as to whether current policies would undergo similar reverses created a degree of scepticism about how genuinely committed different local actors were to collaborative approaches. For leaders of local schools the issue of trust was often raised in relation to the extent to which they would be allowed to define their school development needs and in response develop their own professional learning programmes. 
There needed to be some trust really of our professionalism, that we were doing what we needed to do... Whereas before it was looking at the local authority and looking at their menu (of training programmes) which came from what they thought that we needed to know, we're much better at looking at our own schools, our own needs. (SIG convenor, March 2017)

Within this uncertain policy context, the Central South Wales Challenge was launched in January 2014. It was seen, in part at least, as a symbolic indicator of one consortium's commitment to collaborative working, but also as a means of cohering and re-focussing school-to-school support.

\section{The Central South Wales Challenge}

The initial design influences on the Central South Wales (CSW) Challenge were provided by the City Challenge programme, which took place in three English city regions (Ainscow 2015). A government instigated initiative, the decision to invest large amounts of additional resources in these contexts reflected a concern regarding educational standards, particularly amongst children and young people from disadvantaged backgrounds. Its success, particularly in London, has been widely reported, leading to extensive debates as to what were the key factors that led to its impact (e.g. Baars et al. 2014; Claeys et al. 2015; Greaves et al. 2014; Hutchings et al. 2012; Kidson and Norris 2014). Relevant to developments in Wales, with its strong inclusive ethos, there is evidence that its success can be explained, at least in part, by the ways in which schools responded to increased diversity within the pupil population (Blanden et al. 2015; Burgess 2014). It was also significant that the programme had a strong political mandate, a factor that has sometimes been missing in subsequent efforts to introduce regional improvement initiatives in other regions (Claeys et al. 2015).

Applying the strategic lessons learnt through City Challenge to Wales required a recognition that the histories and politics of competition and collaboration vary across contexts. In particular, there existed a broad political rejection to more competitive 'free' market approaches, and this was combined with a desire to create a unique 'Welsh approach' to challenging the link between social deprivation and under achievement (Welsh Government 2014).

The CSW Challenge programme involves a partnership of just over 400 schools, across five local authorities, including the capital city, Cardiff. Instigated by the Directors of Education, it received the endorsement of local politicians, providing the mandate that seems to have been so important to the success of previous regional Challenges (Claeys et al. 2015). The principles that underpinned the initiative, developed in consultation with schools in the region, were as follows:

- Schools are communities where collaborative enquiry is used to improve practice;

- Groupings of schools engage in joint practice development

- Where necessary, more intensive partnerships support schools facing difficulties; 
- Families and Community organisations support the work of schools;

- Coordination of the system is provided by school leaders;

- Local authorities work together to act as the 'conscience of the system'. (Central South Consortium 2016, p. 3)

These principles reflect the influence of City Challenge in England, as well as the Welsh government's interpretation of the idea of a self-improving system, noted above. Importantly, it places the responsibility for the co-ordination of the system on to the shoulders of school leaders, while positioning local authorities as 'the conscience' of the system, that holds them and the consortium to account.

The espoused aim of requiring school leaders to co-ordinate the new collaborative system was enacted in practice by the creation of a strategy group, consisting of local head teachers, representing each of the authorities and all phases of the system. The group itself was not an operational decision-making forum; rather, it set the overall direction of the Challenge. However, members of the group did take on important roles as 'associates'.

Associate head teachers were partnered with staff from the consortium, who were mainly seconded from local schools, and became directly involved in leading collaborative working and the setting up of new structures. The Challenge was nested within national and local governance structures by the use of various stakeholder and advisory groups, whose roles were framed by the legal agreements that had constituted the consortium.

In what follows we describe and analyse what happened when these collaborative school improvement approaches were adopted and adapted in Wales, a country that has a very different policy context to that of England. This account illustrates the importance of contextual factors related to history, geography, language, cultures and, of course, policies. Incorporating and enacting these collaborative improvement strategies into a cohesive strategy for transitioning a whole system, however, would require leadership and effective facilitation. In this way, the development of the CSW Challenge can be seen as an intermediary structure, capable of avoiding the pitfalls associated with more collaborative ways of working (Ainscow 2015), whilst developing the overall capacity of the regional system to become self-improving.

\section{Gathering evidence}

The analysis we go on to develop in this paper draws on our 'insider' involvement as researchers employed as advisers within the CSW Challenge, contributing to its design, implementation and formative evaluation. This points to a rather obvious methodological challenge regarding the analysis we present. As researchers, we were provided with remarkable opportunities to put into practice ideas that had emerged from many years of investigating ways of developing more equitable schools and education systems. At the same time, we were provided with privileged access to information about how decisions are made within an education system. On the other hand, as people charged with the task of championing the 
project, how far can our interpretations be trusted, not least because our efforts to collect data about the processes involved were often carried out in an incidental way?

We addressed this methodological challenge by triangulating the evidence we collected from different perspectives, using three sets of strategies, as follows:

- Assessing the impact Here the main sources of data were student test scores, teacher self-assessments, school inspection data and responses to an annual survey of leaders, teachers and students. The survey sampled some $20 \%$ of schools from across the region, chosen to reflect both school performance and the percentage of students on role from socially deprived contexts. The staff and pupil surveys were carried out in October 2016 and 2017 and on each occasion generated over 800 responses from staff concerning their involvement in cross-school working and its effects, and some 3,400 responses from students aged 10-16 concerning teaching and learning in their schools.

- Theories of change Each major collaborative strand in the Challenge underwent a theory of change evaluation (Connell and Klem 2000), based upon an initial logic model created by the strand leaders. The model for each strand contained key proxy indicators for the expected impact of the activities upon the individuals and schools involved and on the local system. Within each strand a range of evaluative data was collected from participants, including questionnaire surveys and interviews.

- Case studies These involved accounts of particular strands of collaborative activity. This paper draws primarily upon the most recent round of case studies, carried out between 2016 and 2017. The cases were selected based upon returns to an annual monitoring process that indicated the scope and depth of their collaborative working.

In addition, we attended many planning meetings, workshops and conferences as participant observers. Drawing on the large amount of data generated over the 4 years, in what follows we describe and analyse what happened in relation to the two questions we posed at the start of this paper.

\section{Strands of collaborative activity}

Within the first 12 months of its existence, the CSW Challenge launched four linked strands of collaborative activities (see Fig. 1), with all schools in the region engaged in at least one of them. Some of the strands replaced an aspect of the previous school improvement service with a more school-based and schoolled alternative. They are inclusive in that they focus upon and engage different aspects of the system. They vary in the intensity of the collaborative work they entail, so are open to a range of schools, and the specific foci of the collaborative work is defined by schools themselves.

In summary, the four strands are as follows: 


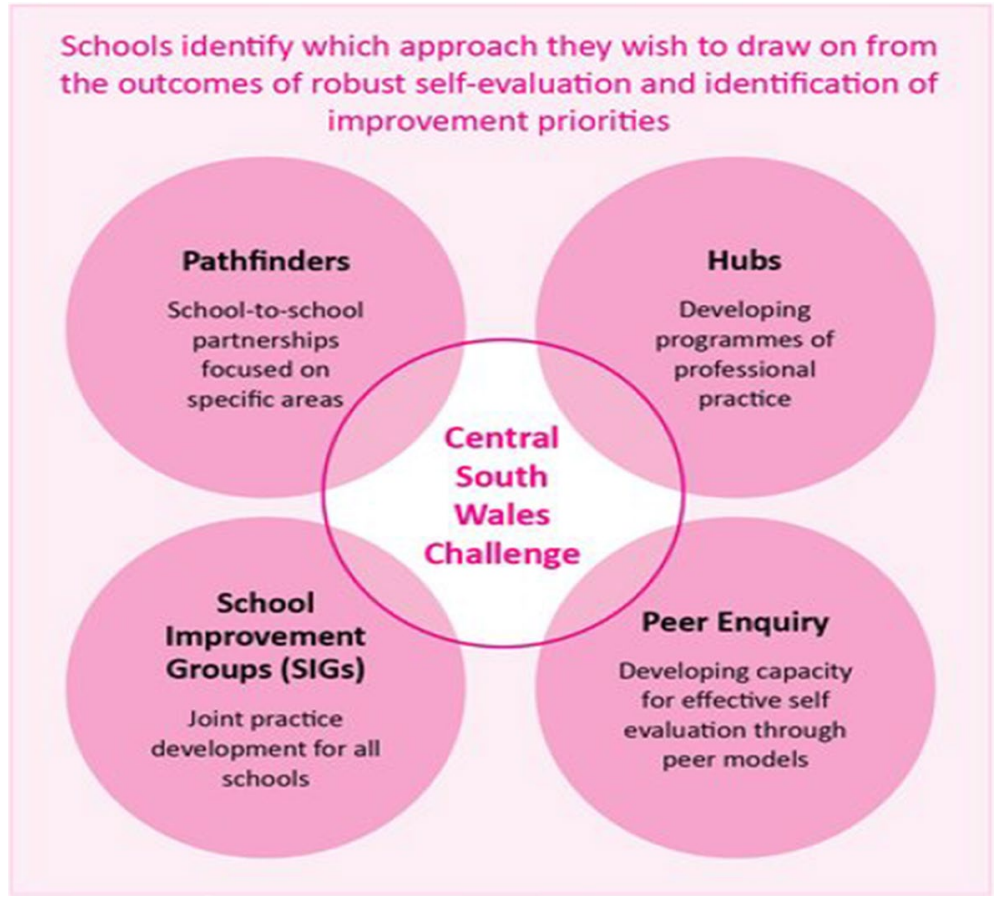

Fig. 1 Main collaborative strands within the Central South Wales Challenge

School improvement groups Early on, the strategy group took the decision to place all schools into School Improvement Groups (SIGs). These were designed to break down barriers between schools, particularly the existing boundaries between local authorities. With this in mind, each SIG consisted of schools from across local authorities, at different points on their learning journey, and with a mix of socio-economic intakes. Initially, 33 primary and 8 secondary SIGs were formed, each made up of between 5 and 12 schools. Each appointed a convenor, which in the first instance tended to be a head teacher. Convenors were provided with training and support to develop a programme of joint practice development based around identifying and sharing existing good practices in order to address shared concerns.

Pathfinder partnerships These pairings were intended to deepen support with the aim of accelerating improvement in schools identified as facing particularly challenging circumstances. The lead schools within the partnerships were higherperforming. The significance of these more focused partnerships to the Challenge was that they provided early evidence of school-to-school school support having a positive impact on the learning and achievement of students.

Hub schools These replaced the professional development offer of the five local authorities. Some 80 hubs were eventually commissioned to develop programmes for practitioners and school leaders, based on a regional needs analysis drawn up by the Consortium. Initially the form of provision mirrored that of the previous 
local authority programmes, in that it was dominated by short, one day or less, courses, although the content was based on hub schools' practices and delivered by their staff. After 2 years the hubs were 're-set' in that they were required to change the nature of their offer by making greater use of enquiry and joint practice development, and to focus on bringing schools and practitioners into collaborative networks and groups. This re-set, instigated by the strategy group, aimed to shift hubs towards the use of more effective forms of professional learning and away from constructing themselves as 'training providers', and towards the facilitation of collaborative sub-structures that would re-enforce and developing existing school-to-school working.

Peer enquiry This strand grew out of the concerns of head teachers of higher performing schools about the lack of support on offer. With this in mind, they designed themselves a systematic process by which senior leaders in different schools could support one another through a process of mutual enquiry. The process went through several iterations and was gradually expanded to involve many more schools, except those in the most challenging of circumstances already in receipt of bespoke support through the pathfinder partnerships.

The speed with which the Challenge implemented these four strands reflected, in part, the effects of the degree of competition between the four regional consortia, which, although officially frowned upon by Welsh Government, had been reenforced by rounds of external inspections and evaluations. Each consortium had pursued different school improvement strategies, reflecting the various political settlements between local authorities and central government as to their roles, and each consortium's commitment and interpretation of the idea of a self-improving system, particularly the extent to which it was to be self-governing.

The CSW Challenge represents the most highly developed approach in respect of collaborative working and devolving responsibility to school leaders, as the other consortia initially maintained most of the elements of a more centrally organised system. In this context, maintaining political and professional commitment to the radical approach adopted by the Challenge required it to be performing at least as well as the other consortia's more traditional approaches.

\section{Evaluating the impact}

At the inception of the CSW Challenge, in 2014, overall pupil performance in the region was below the national average, in that in key stage 4 (students aged 14-16) performance in national tests (GCSE exams) only $54.1 \%$ of pupils achieved the 'Level 2 threshold' (achieved when they gain $5 \mathrm{~A} * \mathrm{~s}$ to $\mathrm{C}$ grade qualifications) compared with a $55.4 \%$ national average. Three years later, pupils' overall performance had improved, so that $60.8 \%$ of pupils achieved the Level 2 threshold, compared to a $60.2 \%$ national average.

The rate of progress in comparison to the other three regions in Wales was commented on during the recent inspection of the consortium. 
The proportion of pupils achieving five $\mathrm{A}^{*}$ or A grades or at GCSE or equivalent has been above the Wales average for the last two years, having improved at the fastest rate across the four regions. (Estyn 2016, p. 4)

This overall trend was driven by improvements in all five authorities, with the two most underperforming improving to the greatest extent and the other three performing above the national average. At the same time, there were encouraging trends in relation to the average progress of pupils eligible for free school meals (eFsM), a key proxy indicator for low income families. The Consortium in 2016 was one of two that exceeded the Welsh government target for the percentage of eFSM pupils meeting the Level 2 threshold. The Consortium demonstrated the most positive trend across all four regions over the last 5 years in respect of the percentage of eFSM pupils achieving the Level 2 threshold, from 19\% in 2011 to $38 \%$ in 2016, the national trend over the same period saw a rise from $22 \%$ to $36 \%$. The early positive trends in pupil attainment were matched by similar trends in the reduction of the numbers of schools categorised as requiring additional support as part of national accountability arrangements.

Over half of the schools in the region are in the higher $50 \%$ when their performance is compared to that of similar schools for all the main indicators... This is the only region where this is the case. Overall, performance in this region has improved at a faster rate than in the other regions over the last three years. (Estyn 2016, p. 4)

The Central South Consortium's position as the most 'improved' region was not formally recognised, as comparisons of the relative performance of the consortia were not encouraged by central government for fear that they would lead to greater competition. At a system level, the overall improvement data provided a degree of protection for the CSW Challenge from both external and internal criticism as it accelerated the pace of transition.

To evidence the extent to which collaboration was a key factor in the gains made by schools, an annual survey of school leaders and staff was launched in 2016 and repeated in 2017. The latest survey indicated that between 2016 and $201764 \%$ of staff in the primary phase and from $57 \%$ in the secondary phase had been involved in working with other schools (Hadfield and Hawkins 2018).

The relatively high levels of staff engagement in school-to-school working provided some positive indications that the Challenge's strategy was having an impact across the system. Evidence that the depth of collaborative working had moved beyond the 'come and see what we are doing variety', criticised by Hill (2013) in the initial evaluation of the consortia, was found in the changing profile of staff collaborative activities. The second survey indicated a gradual deepening of the forms of collaborative projects being undertaken. In the first survey just over a third of staff that had worked on a school to school project had engaged in collaborative working that involved some form of joint practice development this had increased a year later to $80 \%$. In 2016 one fifth of the staff who had worked with another school had under taken a collaborative enquiry into teaching and learning a year later this had increased to $70 \%$ (Hadfield and Hawkins 2018). Although no direct causal link can 
be made between the work of the Challenge and increased staff engagement in forms of collaborative professional learning likely to being about classroom improvement the first survey took place just after the re-set of the Hub schools and as the SIG programme became increasingly focussed on deepening and extending collaborative working and the second survey was completed a full school year after these changes had come into effect.

Evidence of the direct contribution made by the various strands of the Challenge to the development of the scope and depth of collaborative working in the region was provided by the evaluations of the four individual strands. The SIGs have maintained relatively high levels of school engagement. Indeed, by year four, only $4 \%$ of schools had been identified as non-participators. Once SIGs had been established, the focus of their development has been on greater depth of collaboration, moving beyond school leaders to encourage classroom practitioners to engage in joint practice development. In the 2-year period, 2015-2017, this focus resulted in teacher involvement increasing by around $30 \%$ (from $63 \%$ in $2015 / 16$, to $91 \%$ in $2016 / 17$ ) and the percentage SIGs that included some form of joint practice development in their work rose to $50 \%$.

Over the 4-year period of their operation, the hub schools' annual engagement with other schools rose from just over half (52\%), to over two thirds $(69 \%)$, and, since the re-set, some $90 \%$ of their work had been based upon enquiry and joint practice development. In its first 3 years the peer enquiry programme had increased engagement from just $4 \%$ (18) of schools in the region, to $23 \%$ (93). The effectiveness of this programme in respect of resulting in positive changes in classroom practices is difficult to assess, due to the self-selected nature of the sample. However, of the primary schools involved in 2016, some $81 \%$ improved their key stage 2 pupil attainment against a regional average of $61 \%$, with $83 \%$ of secondary schools improving their key stage 4 student attainment against a regional average of $70 \%$. Meanwhile, the pathfinder partnership strand grew from eleven partnerships to more than seventy over the 4 years.

\section{The effects of competition and collaboration on a self-improving system}

The existing patina of collaboration and competition within the region affected the development of the Challenge at multiple levels. In particular, it appeared to constrain certain interactions and, to varying degrees, preconfigured the approaches that were eventually adopted. It also formed the basis for new professional and organisational networks that would reconfigure the local system. To analyse the effects on the nature of the self-improving system that emerged after the first 4 years of the Challenge, in what follows we apply a theoretical framework more often used to study the mobilisation of collective social movements (Hadfield and Chapman 2009).

The specific theory we use views collaboration and competition as arising from the interplay of a range of different interest and identity-based groupings (Fominaya 2010). Although there are dangers in treating these as two distinct forms of groupings - rather than as different aspects of the dynamics of collaboration-analytically it was felt worthwhile in this instance to distinguish conceptually between 
'competition' and 'collaboration'. From this perspective, the interactions between interest-based groupings and agendas that focused upon 'wringing power and benefits from the existing system' (Tilly and Wood 2015) would be deemed as being competitive. Collaborative interactions would focus upon 'recasting' or transforming a system in line with new possibilities and tensions, and those that generated solidarity and commitment around new collective 'valued identities' (Mische 2003), or the re-affirmation of existing identities within new systems. This did not preclude the possibility of there being communities that were both interest and identity based, or that a community might exhibit strong or weak forms of either forms of interaction.

This theoretical framework was applied to two general levels of interactions: the macro level of the overarching strategy used by the Challenge to develop new collaborative structures; and the meso-level interactions of groups of school leaders within specific strands of the Challenge. In this instance we focus upon the work of the SIGs as they provide insights into the complex interactional structures operating at multiple scales that generated different forms of self-governing collaborative structures.

The overarching strategy The overall implementation strategy adopted by the Challenge was termed a 'scope to depth' approach (Hadfield 2017), as it initially focused on the widespread mobilization of school leaders and practitioners in collaborative working and school-to-school support, before gradually deepening the intensity and effectiveness of this way of working. This reflected three key characteristics of the existing patina of collaboration within the broader professional context in which the Challenge operated.

Firstly, there existed a high degree of fragmentation within the system, which had arisen nationally due to the reported lack of trust between the 22 local authorities and across different tiers of the system (Evans 2015; Dixon 2016). This had suppressed previous attempts to develop collaborative ways of working, whether generated from the 'bottom up' or 'top down' (Hadfield 2017), due to concerns over reciprocity and the extent to which aspects of the system would maintain their commitment. By rapidly expanding the number of schools and practitioners involved, the CSW Challenge hoped to increase levels of trust and establish supportive professional norms around collaborative working.

Secondly, at the system level, whilst competition between schools is a driver of improvement in Wales, it is not as significant a policy lever as in other UK education systems, notably England, because of the Welsh government's opposition to quasimarket approaches. The particular socio-economic conditions within Wales meant that competition between schools for students was restricted to relatively few urban contexts. Existing patterns of competitive interactions were, therefore, less likely to be a major influence on schools' willingness to participate in collaborative working.

Thirdly, Wales had historically seen lower levels of engagement in enquiry as a school improvement approach, in comparison with other parts of the UK, due to policy and funding differences. The lack of a critical mass of experienced school leaders and practitioners would have limited the scope of the Challenge if it had initially restricted its collaborative work to processes that required a substantive knowledge of school-based enquiry methods. 
In combination, early positive trends in the improvement data and the rapid increase in collaborative working helped to normalise the idea of a more selfimproving system within the region. Normalisation was an important step in establishing the validity of a range of new forms of professional identities, from SIG convenors to Hub leads, but also generating commitment to a new more 'expansive' form of professionalism whose remit extended beyond the confines of individual schools.

SIGs as co-operative connectives or collegiate collaboratives As noted above, SIGs were based on groups of schools that had been brought together to cross preexisting boundaries and with a degree of sensitivity to existing patterns of competition. SIGs were specific to either the primary or secondary phases, and so experienced different pre-existing degrees of competition and collaboration the effects of which were highlighted by categorising them by the extent to which they had developed as what we call co-operative connectives, in which schools pursue individual but common goals, or as collegiate collaboratives that focus on developing collective responses to a relatively small number of issues

The largest of the secondary SIGs was a good example of a co-operative connective, operating with up to nearly 20 school improvement foci at any one time. Each foci was taken forward by a form of smaller, cross-school professional learning group, known as SIGlets. The foci for their work were drawn from individual schools' development plans and their areas of expertise. We were told that schools could 'dip in and dip out as we need to', across the SIGlets. This provided a structural means of managing potential conflicts of interest, as their membership could be arranged so that, although certain schools within the overall connective might be in competition, this could be avoided within individual SIGlets. One head teacher commented:

We don't compete against each other in terms of families of schools, or anything like that, so everybody has been open and honest from the word go.

Cooperative connectives as structures seemed to enshrine the idea of 'coopetition' (Muijs and Rumyantseva 2014), or 'collaborative advantage' (Huxham 1996) and the role played by interest-based groupings. They provided their members with what was described by one school leader as 'a fantastic forum to share innovative ideas, to have check and balance conversations' with 'routes of the information (that) are a lot tighter and seamless', and give them pre-warning of upcoming changes that helps them get 'ahead of the game'. Connectives were less transformational in their approach to improvement. Rather, they favoured the re-instating, in a school-based form, of valued elements of the previous school improvement system, such as in the case of the SIG in question the setting up 'a mini-advisory service' of specialists across the schools that could support departmental reviews.

SIGs that operated more as collegiate collaboratives adopted more identity-driven approaches to mobilising others based on a search for shared issues around which they would cohere by developing a collective response. The adoption of more identity-driven approaches might involve articulating a shared set of values or aspirations around teaching and learning, selecting a shared symbolic issue, or creating the sense of 'belonging to one big school'. In one SIG, for example, all the head 
teachers from the eleven primary schools involved undertook learning walks in each others' schools during a three-day period, before agreeing what would be their foci. The walks were loosely concerned with the 'learning environment' but, in terms of the formation of the SIG, they were part of ensuring they all shared a 'common cause'. One of the heads explained:

We trust each other but need that common cause that you're doing it for the benefit of the children. I think we have all got that common cause, that we want the best learning experience possible for the children however that may be. And I think if you got that as your core concept, as long as that's what you're all trying to do, then you're going to be alright and everything else will fall into place.

The collegial aspects of these forms of SIGs was expressed in members' commitment to transforming local systems based on enhancing their own and others professional autonomy. For example, by giving teachers much greater responsibility for leading change:

For too long within [this authority] it's always been heads and leaders attending courses and feeding back to staff, whereas now we're changing that around.

We're getting our quality staff out there.

SIGs that attempted to re-structure their local system based on finding a common cause and taking mutual responsibility for its improvement were driven by identitybased mechanisms that evoked a very different sense of what it meant to a school leader or classroom practitioner. Externally, these collaboratives were still part of other sub-systems that required them to work in more hierarchical structures and presented them with competing alternative professional identities. Here, for example, one head teacher contrasts the way of working within her SIG and the pressures she feels under when working as part of a local feeder school 'cluster' of primary schools centred around a secondary 'church' school that has its own 'on-going business':

Yes, I think within the SIG we started with very much our own agenda, the cluster groups have their on-going business, the church cluster... the agenda tends to be set and predefined pretty much... it does tend to be the business for the church.. and transition (of pupils from the primaries to the secondary school) normally predominates what we are heading towards.

\section{Making sense of transition: The role of intermediary structures}

Our involvement in the CSW Challenge provided us with opportunities to study the transitional dynamics of a local education system as it attempted to move from a centralised approach to school improvement, to one led by clusters and networks of schools. At the national level, the work of the Challenge was framed by the policies that had led to the amalgamation of local authority school improvement services into regional consortia and the promotion of the idea that the system should become increasingly self-improving. At the regional level, the 
Challenge's efforts to engage school leaders and practitioners in the transition to a more school-led approach drew it, and them, into the political dynamic between central and local government. Particularly in its initial stages, when the Challenge was involved in disassembling the existing structures and recruiting and mobilising local school leaders to develop new structures, it had to operate as much as a leader and co-ordinator of a professional movement, as it did the catalyst for system re-design.

In modelling how the Challenge functioned as an intermediary structure, we recognised the importance of it responding to the political and cultural dynamics of transition, but also that the key driver was the development of requisite individual, organisational, and system level learning to promote a polycentric approach. Our theoretical starting point was that establishing a polycentric system required the creation of sufficient interlocking networks, or sub-systems, of school leaders and groups of schools to deal with the region's systemic school improvement issues. Individually each sub-system would have the capacity to problem solve independently, innovate, and engage in sustained collaborative reform efforts around specific issues. A successful transition would see the establishment of sufficient interconnected sub-systems within the region to tackle the range of issues it currently faced and to respond coherently to new challenges.

In theoretical terms, the various strands of the Challenge-the SIGs, hub schools, pathfinders and triads of peer enquirers-each represented a distinct mechanism for establishing a different type of sub-system. Those coordinating the Challenge had to ensure operationally the effectiveness of each mechanism, while maintaining a strategic overview of the capacities being generated at an individual, organisational and system level, and the extent to which these met local school improvement needs. They therefore had to identify, and learn how to facilitate, successful sub-systems, and then assimilate and apply this learning to each strand. In terms of its own organisational learning, leading a system level transition placed enormous emphasis upon the Challenge's absorptive capacity (Cohen and Levinthal 1990; Zahra and George 2002; Farrell and Coburn 2017) with respect to how it learnt from each strand and applied this to its overall strategy.

In Fig. 2 we present a model that attempts to explain how the Challenge brought about the transition of the local system. It is based on operational and strategic interactions with the existing capacity of the local school system, and its responsiveness to the practical, political and professional contexts within which it operated. How the Challenge re-calibrated its approach during the transition to accommodate these dynamics is the key to understanding its implementation strategy, how the strategy evolved over time, and the nature of the transition that resulted.

As noted above, the Challenge initially adopted a scale to depth approach to implementation, based on quickly establishing the broad scope and scale of collaborative working. This focussed on bringing together existing individual and organisational capacity, and then aligning it around distinct areas of collaborative working, before attempting to deepen the work so that it could generate additional capacity. The simultaneous launch of four different strands of collaborative working was the practical expression of this scale to depth approach. The implementation strategy reflected concerns not only about the existing capacity within the system, but also 


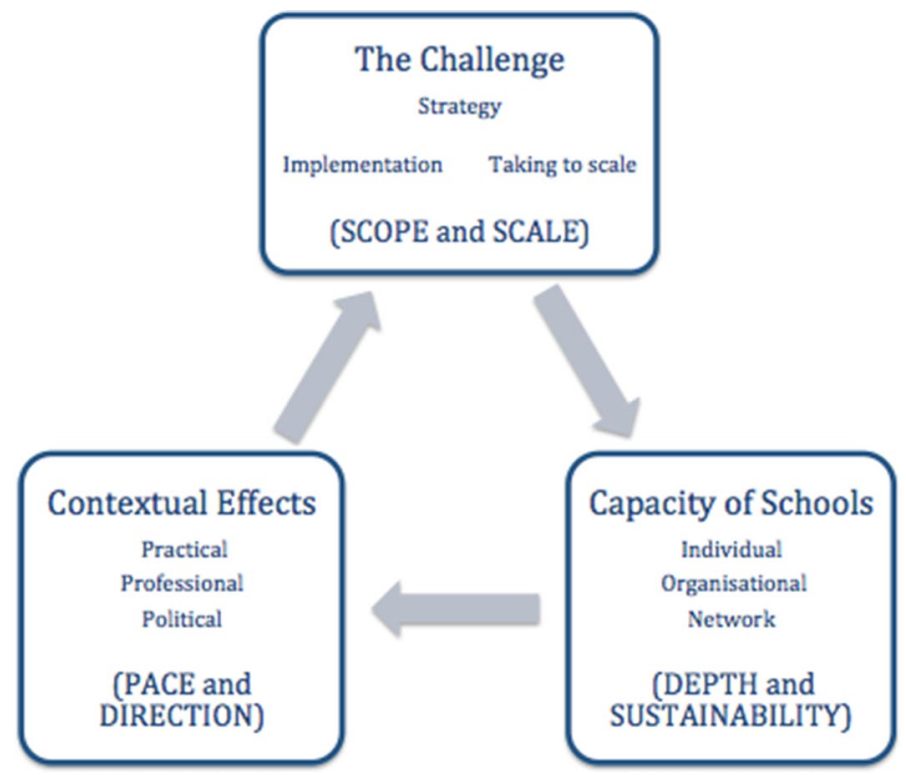

Fig. 2 The transitional dynamics of system level learning

how its development might be affected by tensions in the political and professional contexts from which the Challenge emerged

At the implementation stage of the Challenge, the capacity within the local school system to develop innovative networks and engage in collaborative school improvement was limited. As noted above, this lack of capacity reflected the limited engagement up to this point of school leaders in Wales in collaborative working and in using inquiry based approaches to school improvement. The capacity available was concentrated in a few schools, and the gap between them and other leaders was perceived as being too great to adopt a more traditional 'depth to scale' approach to implementation, by for example creating groups of pilot networks and then taking these to scale across the region.

The Challenge's 'scale to depth' approach involved rapidly increasing the amount of resourcing that went into cross-school collaborative working, by an equally rapid reduction of its funding of more traditional forms of support. As we have explained, in order to create scale, all schools in the region were placed into SIGs that crossed traditional authority boundaries. Schools that had the capacity to work collaboratively became hubs and were funded to provide a school-based regional professional development offer. To ensure that the scope of collaborative working encompassed all sections of the system, new pathfinders were launched to support schools seen as most at risk of underperforming. Meanwhile, the peer enquiry strand supported the leaders of higher achieving schools in learning from one others' approaches to school improvement.

The initial strategic aim was to rapidly expand the number of practitioners who had experience of working collaborative across schools, even if initially much of 
the work was at a relatively low level. Quickly establishing collaborative working at scale, and ensuring that its scope was not restricted to certain types of school improvement work was, in part, driven by the nature of the political and professional contexts from which the Challenge emerged. The political context-particularly the continuing lack of trust between central government, the consortia and local authorities-meant that there were concerns over the degree of political commitment to a more school-led system. Indeed, some school leaders, based on their experience of previous school improvement policies, were concerned that moves towards greater collaboration and professional autonomy might be reversed at any point.

Commenting on this theme, Fink (2016) notes that there is an evolving body of evidence that shows the importance of trust in educational growth and development. To take an example, after an analysis of educational change literature, Robinson (2011) concludes that 'there is compelling evidence that the level of trust among the members of a school community makes an important difference to the way they work together and to the social and academic progress of students (p. 34).'

The Challenge dealt with the perceived lack of trust and the political sensitivities around the self-improving system by positioning itself initially more as an initiative to break down the historical barriers between schools, that had re-enforced the vested interest of local authorities but limited innovation. It was also presented as a way of exchanging good practice, rather than as an explicit attempt to develop new sets of of individual and collective identities based around a school-led system, with all the potential implications for existing power relationships.

The overall professional context was one in which the majority of school leaders had been enculturated into a hierarchical system that required deference to those in 'higher' positions and, when conflict did arise, tended to result in passive rather than active resistance. Engagement in the Challenge was viewed initially as, in part, a symbolic rejection of the existing culture of deference and the establishment of a more professionally assertive cohort of school leaders. Quickly normalising collaborative working across a range of areas, from leadership development to professional learning, was seen as key to the mass mobilisation of school leaders across the region, a mobilisation that would make it a professional movement whose momentum would be much more difficult to disrupt.

Once collaborative working and school-based provision had become normalised to some degree, the Challenge set out to increase its depth and sustainability. This required the use of approaches that varied across the four strands but focussed initially upon those individuals and organisations that had demonstrated a high degree of engagement.

In terms of individual capacity building, moving from 'scale to depth' involved the training and support of those senior practitioners who initially volunteered to be the SIG convenors, hub leaders and the leads of peer enquiries. To ensure a degree of sustainability, the Challenge started to recruit 'sub-system' leadership at various levels, beyond that of those senior school leaders who had already become involved.

The move towards greater depth of collaborative working meant increasing individual engagement in joint practice development and inquiry. For example, after 12 months, the hub schools were 'reset', as their initial offer had too closely mimicked that provided by the local authorities, which, although school-based, still 
consisted of numerous short courses in areas of perceived expertise. This required them to adopt a professional practice, rather than a professional knowledge approach, based on collaboratively inquiry amongst groups of schools. This was intended to move hubs on from constructing themselves as providers of training programmes, to becoming facilitators of new innovation and learning networks. Hubs would, in time, become key to the creation of numerous sub-systems across the region.

As innovation and learning networks formed into sub-systems that could engage in deeper and sustained forms of collaboration, different aspects of the local education landscape began to vary in the extent to which they became self-improving. The Challenge attempted to affect the pace and direction of these transitions, so that subsystems could function interdependently, by interceding between different aspects of the local and national systems. For example, as the Challenge developed sustainable local networks, central government began to utilise these as a means of implementing a programme of national curriculum reform. The effect of this co-option was to re-direct the focus of some of the region's most effective networks away from collaborative school improvement, potentially strengthening the work of these individual networks at a cost of weakening the system as a whole. The Challenge, in this instance, responded by re-directing resources to new hubs, while embedding the centrally funded hubs more securely within the regions existing SIG networks.

Throughout these transitions, the Challenge had to be responsive to both the external and internal contexts in which it operated. It therefore had to have sufficient adaptive and responsive capacity (Parent et al. 2007; Mortruex and Barnett 2017) to ensure that changes in the political, professional and practice agendas-at both local and national levels - did not unbalance the process of transition.

\section{Drawing conclusions}

In developing the work of the CSW Challenge, a useful starting point was the conceptual work carried out by David Hargreaves in relation to developments in England. He argues that there are four 'building blocks' for the development of a selfimproving system: capitalising on the benefits of clusters of schools; adopting a local solutions approach; stimulating co-construction between schools; and expanding the concept of system leadership (Hargreaves 2010, 2011, 2012a, b). He further suggests that, in order to move forward, these building blocks have to be strengthened, so that schools collaborate in using more effective forms of professional development and school improvement. However, Hargreaves left unanswered the question as to how such 'strengthening' would occur and, therefore, how a self-improving system might be brought about.

Drawing on our experiences of the Greater Manchester Challenge (Ainscow 2015), and of previous national collaborative initiatives in the UK (e.g. Excellence in Cities; Educational Action Zones; Networked Learning Communities), in this paper we have highlighted how the patina of collaboration and completion effects attempts to 'strengthen' a system at different levels. We have argued for the importance of viewing system change as being akin to launching a professional 'movement' and how the initiation and mobilisation of such a movement arises from the 
formation and interaction of communities that are driven by issues of both interest and identity. By studying the work of the Challenge we have gained insights into the dynamics of system transition and the role such intermediary structures play in 'strengthening' approaches to school improvement based on collaborative organisational learning and innovative sub-systems of schools and individuals. We draw on both sets of insights to suggest principles for designing an intermediary structure that can bring about just the kind of system strengthening discussed by Hargreaves (2012c).

In so doing, we also keep in mind the idea of 'coopetition', noted earlier, particularly the conditions that Muijs and Rumyantseva (2014) suggest are needed in order for it to be effective; i.e. partners who see clear and tangible benefits from collaboration; trust between partners, established through the careful development of relationships amongst key actors; clear goals and agreements between partners; and forms of leadership that are skilful in managing tensions.

Keeping these ideas in mind, our involvement in the CSW Challenge leads us to argue that an intermediate organisation that can facilitate system level transition requires structures and processes that are capable of the following:

- On-going contextual analysis of a local system's existing capacity for collaborative school improvement This has to be capable of identifying areas of outstanding practice, drawing out of key learning and applying this to the development of the necessary human and social capital to support system level improvement efforts.

- Brokerage, within and between networks, that crosses professional and social boundaries This is in order to increase exposure to various sources of expertise and innovative practices. It requires the orchestration of different forms of individual and organisational networks into integrated sub-systems capable of fostering system level improvements, even in challenging circumstances.

- The development of capacity for leadership at all levels of a system This must be capable of leading collaborative learning within and between schools. It requires the micro-mobilisation of successful head teachers to take on system leadership roles, in combination with the macro-mobilisation of sufficient school leaders at all levels to create a professional movement with sufficient momentum to overcome internal and external resistance.

- The creation and maintenance of a strong political mandate at the national and local levels This is intended to create the conditions within the system that are supportive of collaborative local action. It requires new thinking, attitudes and relationships across education systems. It also requires that inequalities of power between elements of the system are addressed.

What connects these design principles in a way that makes them coherent is the way they focus attention on the importance of managing and interconnecting individual, organisational and system level learning, within complex transitional dynamics. These learning processes also help to make the familiar unfamiliar in ways that challenge expectations as to what is possible, whilst, at the same time, drawing attention 
to examples of different ways of working that can act as the focus of joint practice development.

Managing the dynamics of system transition in a way that enhances its capacity for self-improvement extends the remit of an intermediary organisation into the political and professional contexts that surround it. Our experience is that system change strategies designed around these propositions have the potential to stimulate collective efforts to explore new possibilities for addressing old problems.

\section{Final thoughts}

As we have shown, there has been massive progress in developing a self-improving system across the Central South Wales region. However, this remains fragile for a variety of reasons. These include the tendency for the Welsh government, like others, to revert to top-down decision making when faced with a need for major policy changes, such as the new national curriculum that is currently being introduced.

There is also the continuing impact of national accountability systemsthe publication of school test scores and inspection reports, and the grading of schools in terms of the degree of support that they require-that tend to discourage cooperation between schools. This also means that school leaders are still spending considerable time preparing progress reports for different audiences, attending various review and scrutiny meetings, and being given different (and at times conflicting) advice on the improvements required and how they can be implemented (Ainscow 2016). The development of a self improving system raises implications for the tasks and responsibilities of the inspectorate. As argued by Ehren et al. (2017), it will increasing require a repositioning of inspectorates as partners within networks of schools and inspection systems that place greater emphasis upon self and peer evaluation processes.

Linked to this, and despite the rhetoric of self-improving systems, actions by some local authority and consortia staff still tend to limit the freedom of school leaders to take responsibility for their own improvement. As a result, this leads to a sense of dependency on outsiders to lead improvement efforts, rather than those within schools sharing responsibility and being accountable for improved outcomes. Some of these difficulties arise because of a lack of clarity amongst local authority and consortia staff about their respective roles and responsibilities within a selfimproving system. The need for certainty in this respect is particularly vital, since the new approach requires radical changes to thinking, practice and relationships at every level.

All of this implies a major rethink of national education policy. In particular, policy makers have to foster greater flexibility at the local level in order that practitioners have the space to analyse their particular circumstances and determine priorities accordingly. This means that policy makers must recognise that the details of policy implementation are not amenable to central regulation. Rather, they have to be dealt with by those who are close to practice and, therefore, in a better position 
to understand local contextual effects, including the possibilities and problems presented by the existing patina of collaboration and competition.

Open Access This article is distributed under the terms of the Creative Commons Attribution 4.0 International License (http://creativecommons.org/licenses/by/4.0/), which permits unrestricted use, distribution, and reproduction in any medium, provided you give appropriate credit to the original author(s) and the source, provide a link to the Creative Commons license, and indicate if changes were made.

\section{References}

Ainscow, M. (2015). Towards self-improving school systems: Lessons from a city challenge. London: Routledge.

Ainscow, M. (2016). Schools challenge cymru: A catalyst for change? Wales Journal of Education, 1(1), 6-22.

Asheim, B. T. (2002). Temporary organisations and spatial embeddedness of learning and knowledge creation. Geografiska Annaler: Series B, Human Geography, 84(2), 111-124.

Baars, S., Bernardes, E., Elwick, A., Malortie, A., McAleavy, T., McInerney, L., et al. (2014). Lessons from London Schools: Investigating the success. London: CfBT Education Trust.

Blanden, J., Greaves, E., Gregg, P., Macmillan, L., \& Sibieta, L. (2015). Understanding the improved performance of disadvantaged pupils in London. Social Policy in a Cold Climate (pp. 2-47).

Burgess, S. (2014). Understanding the success of London's schools. Centre for Market and Public Organisation (CMPO) Working Paper, 14, 333.

Central South Consortium. (2016). Central South Consortium Business Plan. Ty Dysgu: Central South Consortium Joint Education services.

Claeys, A., Kempton, J., \& Paterson, C. (2015). Regional Challenges: A collaborative approach to improving practice. London: Centreforum.

Cohen, W. M., \& Levinthal, D. A. (1990). Absorptive capacity: A new perspective on learning and innovation. Administrative Science Quarterly, 35(1), 128-152.

Connell, J., \& Klem, A. M. (2000). You can get there from here: Using a theory of change approach to plan urban education reform. Journal of Educational and Psychological Consulting, 11(1), 93-120.

Department for Education. (2010). The importance of teaching (The schools White Paper). London: Department for Education.

Department for Education and Skills. (2013). The future delivery of education services in Wales: Consultation document. Cardiff: Welsh Assembly.

Department for Education and Skills. (2014). Qualified for Life. An education plan for 3 to 19-year-olds in Wales. Cardiff: Welsh Government.

Dixon, P. (2016). Testing times: Success, failure and fiasco in education policy in Wales since devolution. Cardiff: Welsh Academy Press.

Ehren, M. C. M., Janssens, F. J. G., Brown, M., McNamara, G., O’Hara, J., \& Shevlin, P. (2017). Evaluation and decentralised governance: Examples of inspections in polycentric education systems. Journal of Educational Change, 18(1), 365-383.

Estyn. (2015). Improving schools through regional education consortia. Cardiff: Estyn.

Estyn. (2016). A report on the quality of the school improvement services provided by the Central South Consortium. Cardiff: Estyn.

Evans, G. (2015). A class apart; Learning the lessons of education in post-devolution Wales. Cardiff: Ashley Drake.

Farrell, C., \& Coburn, C. (2017). Absorptive capacity: A conceptual framework for understanding district central office learning. Journal of Educational Change, 18(2), 135-159.

Fielding, M., Bragg, S., Craig, J., Cunningham, I., Eraut, M., Gillinson, S., et al. (2005). Factors influencing the transfer of good practice. Nottingham: DFES Publications.

Fink, D. (2016). Trust and verify: The real keys to school improvement: An international examination of trust and distrust in education in seven countries. London: UCL IOE Press.

Fominaya, C. (2010). Collective identity in social movements: Central concepts and debates. Sociology Compass, 4(6), 393-404. 
Greaves, E., Macmillan, L., \& Sibieta, L. (2014). Lessons from London schools for attainment gaps and social mobility. London: Social Mobility and Child Poverty Commission.

Hadfield, M. (2017). Decentralisation, localism and the role of PLCs in supporting school collaborations in Wales. In A. Harris, M. Jones, M. \& J. Huffman (Eds.), Teachers Leading Educational Reform: The Power of Professional Learning Communities (pp. 210-227). London: Routledge.

Hadfield, M. \& Chapman, C. (2009). Leading school based networks. London: Routledge.

Hadfield, M., \& Hawkins, J. (2018). Second annual school staff survey. Ty Dysgu: Central South Consortium.

Hargreaves, D. H. (2010). Creating a self-improving school system. Nottingham: National College for School Leadership.

Hargreaves, D. H. (2011). Leading a self-improving school system. Nottingham: National College for School Leadership.

Hargreaves, D. H. (2012a). A self-improving school system in international context. Nottingham: National College for School Leadership.

Hargreaves, D. H. (2012b). A self-improving school system: Towards maturity. Nottingham: National College for School Leadership.

Hargreaves, D. H. (2012c). A self-improving system in international context. Nottingham: National College for School Leadership.

Hill, R. (2013). The future delivery of education services in Wales. Cardiff: Welsh Government.

Hutchings, M., Greenwood, C., Hollingworth, S., Mansaray, A., Rose, A., \& Glass, K. (2012). Evaluation of the City Challenge programme. London: Institute for Policy Studies in Education.

Huxham, C. (1996). Creating collaborative advantage. London: Sage.

Huxham, C., \& Vangen, S. (2004). Doing things collaboratively: Realizing the advantage or succumbing to inertia. Organizational Dynamics, 33(2), 190-201.

Kidson, M., \& Norris, E. (2014). Implementing the London Challenge. London: Joseph Rowntree Foundation.

Lingard, B., \& Lewis, S. (2016). Globalisation of the Anglo-American approach to top-down, test based educational accountability. In G. T. L. Brown \& L. R. Harris (Eds.), Handbook of human and social conditions in assessment (pp. 387-403). New York: Routledge.

Mische, A. (2003). Cross-talk in movements: Reconceiving the culture-network link. In M. Diani \& D. McAdam (Eds.), Social movements and networks: Relational approaches to collective action (pp. 258-280). Oxford: Oxford University Press.

Mortruex, C., \& Barnett, J. (2017). Adaptive capacity: exploring the research frontier. WIREs Climate Change. https://doi.org/10.1002/wcc.467.

Mourshed, M., Chijioke, C., \& Barber, M. (2010). How the World's most improved school systems keep getting better. London: McKinsey \& Company.

Muijs, D., \& Rumyantseva, N. (2014). Coopetition in education: Collaborating in a competitive environment. Journal of Educational Change, 15(1), 1-18.

NFER. (2007). Inter-school collaboration: A literature review. Slough: NFER.

OECD. (2014). Improving schools in Wales: An OECD perspective. Paris: OECD.

Ostrom, E. (2010). Beyond markets and states: Polycentric governance of complex economic systems. Transnational Corporations Review, 2(2), 1-12.

Parent, R., Roy, M. \& St-Jacques, D. (2007). A systems-based dynamic knowledge transfer model. Journal of Knowledge Management, 11(6), 81-93.

Rincón-Gallardo, S., \& Fullan, M. (2016). Essential features of effective networks in education. Journal of Professional Capital and Community, 1(1), 5-22.

Robinson, V. (2011). Student-centered leadership. San Francisco, CA: Jossey-Bass.

Salokangas, M. \& Ainscow, M. (2017). Inside the autonomous school: making sense of a global educational trend. London: Routledge.

Tilly, C., \& Wood, L. J. (2015). Social movements 1768-2012. London: Routledge.

Wales Audit Office. (2015). Achieving improvement in support to schools through regional education consortia-An early view. Cardiff: Wales Audit Office.

Welsh Assembly Government. (2014). National model for regional working. Cardiff: Welsh Assembly.

Zahra, S. A., \& George, G. (2002). Absorptive capacity: A review, reconceptualization, and extension. The Academy of Management Review, 27(2), 185-203. 